\title{
PROCESSO DE IDENTIFICAÇÃO E CONSTRUÇÃO DISCURSIVA EM UMA ORGANIZAÇÃO POLICIAL
}

\section{IDENTIFICATION PROCESS AND DISCURSIVE CONSTRUCTION ON A POLICE} UNIT

Adriana Ventola Marra Universidade Federal de Viçosa/Campus Florestal - MG aventola@ufv.br

Jeferson Aderbal Fonseca Universidade Federal de Minas Gerais / Polícia Militar de Minas Gerais jeferson.ufmg@gmail.com

Mariana Mayumi Pereira de Sousa Universidade Federal de Minas Gerais mariana.mayumi@ufv.br

Submissão: $25 / 02 / 2015$

Aprovação: 13/06/2016 


\title{
RESUMO
}

Este artigo teve por objetivo analisar o processo de identificação de policiais militares da Polícia Militar de Minas Gerais. Buscou-se explorar como as "escolhas" desses sujeitos foram realizadas e se refletem em suas práticas discursivas. O eixo teórico que sustenta as análises pautou-se na dicotomia entre identidade pessoal e social, na Teoria da Identidade Social e em suas implicações para o entendimento dos processos de identificação. Trata-se de uma pesquisa qualitativa de caráter exploratório, em que foram realizadas dez entrevistas em profundidade, analisadas pela Análise Crítica do Discurso. As representações (discursos) dos policiais militares foram dialeticamente internalizadas em maneiras particulares de ação (gêneros) e em modos específicos de identificação (estilos). Desta forma, foi possível verificar como discursos dos grupos do alto comando da Corporação e demais discursos sociais e culturais foram inculcados nas identidades dos policiais e como as constituem.

Palavras-chave: Identificação. Discursos. Policiais Militares.

\begin{abstract}
This article aims to analyse military police officers' identification process in Minas Gerais Military Police. We sought to explore how these subjects' "choices" were performed and reflected in their discursive practices. For this analysis, our theoretical background was based on the dichotomy between personal and social identity, on Social Identity Theory, and its implications for understanding identification processes. This is a qualitative exploratory research. Ten in-depth interviews were conducted and analysed by Critical Discourse Analysis. The police officers' representations (discourses) were dialectically internalized by particular actions (genres) and by specific identification modes (styles). Thus, it was possible to verify how discourses from high command groups and other social and cultural discourses were inculcated in the officers' identities and how these identities were constituted.
\end{abstract}

Keywords: Identification. Discourse. Police. 


\section{INTRODUÇÃO}

As organizações podem ser vistas como locais privilegiados para o desenvolvimento de processos identificatórios e construção de identidades. A partir desta constatação, esses temas, bastante complexos e relevantes, têm sido investigados por vários campos do conhecimento e assumem uma diversidade de definições e empregos nas diferentes disciplinas. Isto é consenso entre vários pesquisadores (DUBAR, 2005; RHODES e BROWN, 2005; ASHFORTH, HARRISON e CORLEY, 2008; YBEMA et al., 2009), tendo em vista que o entendimento dos processos de constituição dos sujeitos no contexto organizacional passa necessariamente pelo estudo destes temas.

Essa diversidade de empregos e definições de identidade e identificação também se repete nas investigações específicas da área de estudos organizacionais. Alvesson, Ashcraft e Thomas (2008) apontam que os estudos sobre identidade e identificação são conduzidos de acordo com diversas finalidades: desde proporcionar soluções para problemas organizacionais vinculados ao comportamento humano, até o interesse emancipatório de se revelar e questionar as estruturas organizacionais, passando pelo intuito de se interpretar a experiência humana no contexto das organizações. Neste artigo, entende-se identidade como um fenômeno social dinâmico (processual e inacabado), construído em um contexto sócio histórico, resultado dos processos de socialização e pautada por atos de atribuição e pertencimento (DUBAR, 2005).

Tendo em vista a diversidade teórica e paradigmática, este artigo tem como objetivo analisar o processo de identificação de um grupo de policiais militares a partir de relatos individuais. Com esse estudo, busca-se explorar como as "escolhas" desses sujeitos foram realizadas e se refletem em suas práticas discursivas. Sendo assim, este trabalho reflete sobre o que são e o que fazem os membros desta Organização Policial.

Considera-se que, para a ampliação do escopo desta pesquisa, o exame das percepções individuais em relação à identificação organizacional deve ser conjugado com a análise de outros discursos organizacionais na medida em que o indivíduo não seria o único responsável pela construção de sua identidade. As relações entre indivíduos, agentes organizacionais, discursos institucionais e culturais/sociais são dinâmicas e recíprocas, influindo diretamente no processo de identificação individual. Entendemos que os "discursos organizacionais" são múltiplos, pois incluem os discursos produzidos pelos indivíduos e os "discursos institucionais", que denotam o discurso proferido "oficialmente" pela organização enquanto 
instituição. Sendo assim, este artigo, ao focar sua análise no indivíduo, traz apenas reflexões iniciais do processo identificatório.

A Organização Policial pesquisada faz parte do Sistema de Segurança Pública do Estado de Minas Gerais, e tem como principal missão a polícia ostensiva de preservação criminal, de segurança, de trânsito, de florestas e de mananciais e as atividades relacionadas com a preservação e restauração da ordem pública.

Ser servidor público na instituição pesquisada apresenta várias peculiaridades que devem ser consideradas. Entende-se a instituição policial militar como uma Instituição Total (GOFFMAN, 1999), considerando que quando os indivíduos ingressam na organização, estes devem procurar adequar os seus anseios e valores ao propósito da instituição. Para o autor, as principais características destas instituições são que todos os aspectos da vida são realizados num mesmo local sob uma mesma autoridade, todas as atividades diárias são realizadas em conjunto com outras pessoas, tais atividades seguem rigorosamente uma sequência, horário e tempo impostos de cima para baixo, e as várias atividades obrigatórias são reunidas num plano racional único. Segundo Goffman (1999, p. 17), “o aspecto central das instituições totais pode ser descrito com a ruptura das barreiras que comumente separam essas três esferas (residência, trabalho e lazer)".

Nogueira e Moreira (1999) ressaltam que as regras de convivência e ideais militares permeiam as relações de e no trabalho. A socialização do policial militar é centrada em princípios rígidos, padronização das condutas, comportamentos, atos e fardamentos instituídos pela doutrina explicitada em documentos tais como o Código de Ética e Disciplina Militares e o Código Penal Militar. Assim, a relação hierárquica da estrutura policial é rígida e calcada em tais códigos de normas e condutas. Dentro desta relação, os papéis de superiores e subordinados são bem delineados (LOPES JR. et al., 2011).

Contudo, Bayley (2001) ressalta que o controle e o delineamento do comportamento policial é exercido por mecanismos localizados tanto dentro quanto fora da polícia: governo, prefeitos, oficiais do ramo executivo, assim como comissões civis, a mídia de massa. Este processo de socialização e controle, característicos das Instituições Totais (GOFFMAN, 1999) tenderia a dificultar o aparecimento do que é individual e singular nos sujeitos, o que, no entanto, não foi o que ficou constatado no presente estudo.

Este artigo está estruturado em sete partes, incluindo esta introdução. Inicialmente, trata-se da discussão da dicotomia entre identidade pessoal e social. Posteriormente aborda-se a Teoria da Identidade Social e suas implicações para o entendimento dos processos 
identificatórios. Passa-se, então, a apontar as opções metodológicas realizadas para a construção deste artigo, trazendo em destaque as considerações sobre a Análise Crítica do Discurso (ACD). Em seguida, apresenta-se uma rápida contextualização da Organização Policial estudada e discutem-se os dados coletados. As análises seguiram a divisão proposta pela ACD, procurando desvelar os significados acional, representacional e identificacional das entrevistas realizadas. Por fim, são tecidas as considerações finais do artigo.

\section{Identidade: pessoal versus social?}

Nos estudos organizacionais, pode-se considerar que o termo identidade serve de base para a construção da transdisciplinaridade entre a Teoria das Organizações e disciplinas como a psicologia, a sociologia e a antropologia. A maioria dos estudos sobre identidade nas organizações reconhece a natureza sócio histórica e a mutabilidade da identidade das pessoas (CARRIERI, PAULA e DAVEL, 2008). Nesse sentido, a identidade não pode ser entendida como fixa e única; ao contrário, ela deve ser vista como fenômeno socialmente construído em dado contexto sócio histórico, estando sujeita a contínuas transformações (BRITO et al., 2008). Cabe ressaltar que, mesmo sujeita a essas transformações, o repertório de conhecimentos, habilidades e atitudes acumulados não é totalmente descartado, constituindo a base para a reconstrução da identidade (ASHFORTH, HARRISON e CORLEY, 2008).

Em abordagens funcionalistas sobre identidade nas organizações, continua comum a separação entre identidades pessoais e sociais. Neste caso, a identidade pessoal normalmente se refere unicamente a atributos individuais, não sendo compartilhada com outras pessoas e não sendo vista como um sinal de grupo de pertencimento. Identidade social, por outro lado, refere-se à percepção de um indivíduo sobre si mesmo como membro de um grupo, em termos de valores e de apego emocional. Os estudos da identidade social, muitas vezes, conduzem a pesquisas sobre identificação organizacional ou em que medida os membros individuais alinham suas noções pessoais de self com identidades coletivas (ALVESSON, ASHCRAFT e THOMAS, 2008).

Apesar dos persistentes argumentos para as diferenciações entre as identidades pessoais e sociais, verificam-se os limites tênues e as relações inevitáveis entre o pessoal e o social que devem ser considerados nas investigações sobre identidade. Essas imbricações entre o pessoal e o social podem ser vistas quando os indivíduos se definem como secretárias, gerentes intermediários ou professores, por exemplo, não implicando simplesmente em vestir uma roupagem, mas sempre envolvendo negociação e interseções com outras identidades 
realizadas simultaneamente (por exemplo, branca, professora, sexo feminino e mãe) e tendo um significado individualizado construído em interação com as pessoas e os sistemas que nos rodeiam. Assim, mesmo quando as pessoas se referem a um nós "aparentemente partilhado", elas imbuem este coletivo despersonalizado de diversos significados personalizados (ALVESSON, ASHCRAFT e THOMAS, 2008). Estas discussões, segundo os autores, confirmam a necessidade da presença da dupla pessoal e social, mesmo em estudos que enfatizam uma ou outra. Algumas teorias realizam esta tarefa, salientando as dimensões relacionais da identidade.

Essa dimensão relacional é enfatizada por Berger e Luckman (2002), que entendem a identidade como resultado do processo de interação em múltiplas realidades e como apreendidas e compartilhadas por meio de processos de socialização. Os autores afirmam que a construção da identidade como fruto da socialização é marcada por movimentos de externalização - forma pela qual o sujeito se revela para o mundo - e de interiorização processo por meio do qual o sujeito apreende novas formas de ação ou se socializa, também chamada de socialização secundária. Estes movimentos dão origem ao processo de institucionalização, em que as ações tipificadas são partilhadas, passando a servir de referência para ação individual e coletiva de todos os indivíduos. O processo de socialização é marcado pela interpretação e pela capacidade reflexiva dos sujeitos, que têm um papel ativo na construção de sua identidade (BERGER e LUCKMAN, 2002).

Outras teorias fazem a ligação entre identidades pessoais e sociais, reconhecendo o discurso e a comunicação como o material central e o mecanismo de produção de identidade, respectivamente. Por exemplo, os teóricos do construcionismo social argumentam: (a) que as identidades pessoais são negociadas, ameaçadas, reforçadas, reproduzidas e revitalizadas por meio da interação, e (b) as identidades pessoais necessariamente baseiam-se nos discursos sociais ou narrativas disponíveis sobre quem se pode ser e como se deve agir, alguns dos quais podem desfrutar apoio institucional (ASHCRAFT e MUMBY, 2004).

Neste sentido, a proposta de análise de Dubar (2005) acerca da identidade torna-se relevante na medida em que se sustenta nos processos de socialização como forma de incorporação do habitus na construção das identidades. Nesta perspectiva, o autor define identidade como o "resultado a um só tempo estável e provisório, individual e coletivo, subjetivo e objetivo, biográfico e estrutural, dos diversos processos de socialização que, conjuntamente, constroem os indivíduos e definem as instituições" (DUBAR, 2005, p.136). Essa dualidade no social, o processo biográfico e relacional, a identidade real e a virtual, o 
caráter dinâmico e complexo, são reforçados quando se afirma que a construção da identidade

pode ser conceituada como um processo complexo e multifacetado que produz um resultado temporário e negociado socialmente por meio da interação dinâmica entre lutas internas e prescrições externas, entre auto-apresentação e rotulagem pelos outros, entre desempenho e atribuição, entre regulação e resistência (YBEMA et al., 2009, p. 301).

Tendo em vista as considerações apresentadas, neste artigo será adotada a concepção de identidade como um fenômeno social dinâmico (processual e inacabado), construído em um contexto sócio histórico, resultado dos processos de socialização e pautada por atos de atribuição e pertencimento. A análise da identidade, nesta perspectiva, coloca em evidência a importância dos processos de identificação que são tratados no item que se segue.

\section{Processos de identificação e a teoria da identidade social}

Possivelmente a mais influente, ou certamente a mais proeminente, corrente teórica em estudos organizacionais de identidade tenha sido a Teoria da Identidade Social (ASHFORTH e MAEL, 1989). Nesta corrente estão relacionadas duas orientações conceituais básicas, associadas aos estudos dos psicólogos sociais Henri Tajfel e John Turner: a Teoria da Identidade Social (SIT) e a Teoria de Auto categorização (SCT). Esta última é, por vezes, incorporada na primeira e os seus termos são utilizados menos frequentemente no contexto de estudos organizacionais. Uma distinção fundamental é que a SIT examina a forma como as pessoas posicionam-se e entendem os outros em termos de categorias de grupo social (ou seja, in-group/out-group). Considerando que a SCT investiga o que leva as pessoas a se verem como indivíduos únicos, em algumas circunstâncias e, em outras, se definem por meio de membros do grupo (protótipos), despersonalizando, assim, os aspectos da identidade (ALVESSON, ASHCRAFT e THOMAS, 2008).

Ashforth e Mael (1989) definem identificação social como "a percepção de unidade ou sentimento de pertença a algum agrupamento humano" (p. 135). Com isso sugerem o agrupamento em unidades sociais como a principal fonte de identidade. Estudiosos desta teoria partem da premissa de que as pessoas se classificam e aos outros com base em grupos e categorias, que podem ser, por exemplo, baseados em sexo, raça, etnia, religião, ocupação, e assim por diante (TAJFEL e TURNER, 1985). Esse sistema de classificação social proporciona aos individuos um meio de se definirem e se identificarem com determinados grupos, ou seja, o autoconceito. O autoconceito, entendido como o modo como o sujeito 
percebe a si próprio em relação a si mesmo e em relação aos outros (TAJFEL e TURNER, 1985), é formado pela soma da identidade pessoal do sujeito e de suas identificações sociais oriundas de sua autoclassificação nos grupos (ASHFORTH e MAEL, 1989).

Ashforth e Mael (1989) enfatizam que esse "agrupamento psicológico", em que vários indivíduos se percebem como pertencentes a uma mesma categoria social e se auto definem como membros integrantes daquele determinado grupo, inicia-se com o indivíduo se comparando com os demais membros da sociedade e se percebendo como distinto e único. Posteriormente à comparação, o mesmo indivíduo passa a avaliar, positiva ou negativamente, os vários grupos sociais existentes. Por meio dessas comparações e avaliações, ele define os outros e a si mesmo, passando a se perceber e aos outros como possuidores ou não das mesmas características inerentes àquele grupo específico. Este processo, além de proporcionar ao sujeito o desenvolvimento de sentimentos de pertencimento a determinados grupos sociais, também viabiliza sua auto definição e a formação de sua autoestima (TAJFEL e TURNER, 1985).

Vale destacar que a principal característica da SIT, então, é um movimento de despersonalização do sujeito que acaba vendo a si mesmo como uma encarnação dos membros protótipos do grupo (STETS e BURKE, 2000). Em estudos organizacionais, a SIT veio à tona, com mais destaque nas pesquisas sobre identificação organizacional. Como descrito, muitas destas pesquisas adotam uma postura funcionalista, investigando qual o grau de identificação com a organização para produzir importantes resultados organizacionais, tais como compromisso, lealdade e motivação (ASHFORTH e MAEL, 1989).

A perspectiva sociológica amplia a definição de identificação trabalhada pelas SIT e SCT, à medida que ela remete aos processos de socialização vividos pelos sujeitos (DUBAR, 2005). Para o autor, a relação entre socialização e auto definição propõe que o senso de "quem a pessoa é" seja agregado ao senso de "onde ela está" e "o que dela é esperado". Desta forma, os sujeitos assimilam a maneira de sentir, agir, ser e pensar de um grupo, incorporando também a sua visão de mundo, sua relação com o futuro, suas possibilidades, bem como interiorizam seus valores, normas e códigos simbólicos.

Estudos funcionalistas sobre identificação organizacional tendem a adotar uma visão bastante estática destas questões: a percepção individual de si e da organização e os níveis de identificação são assumidos como relativamente estáveis, e a organização é tratada como principal objeto de identificação. Alguns estudos recentes têm desafiado tais pressupostos, desencadeando uma maior sensibilização da identificação como um processo complexo e 
fluido. Diversos autores, por exemplo, agora estudam múltiplos alvos de identificação, reconhecendo a "organização", como uma entidade formal e abstrata, em que coexistem vários discursos que podem, alternada ou simultaneamente, servirem de fontes de identificação (YBEMA et al., 2009; ALVESSON, ASHCRAFT e THOMAS, 2008, PRATT e FOREMAN, 2000).

Também, se pode argumentar que mesmo encarada como um único alvo ou discurso, a "organização" significa coisas diferentes para pessoas diferentes em momentos diferentes (ASHCRAFT e ALVESSON, 2007). Noções de "nós" variam amplamente em função da pessoa e do contexto. Outra questão relevante que merece destaque é que os sujeitos não são totalmente "livres" em seu processo de identificação, mas parcialmente constrangidos pelas estruturas sociais (FAIRCLOUGH, 2003). Em outras palavras, pode-se dizer que o indivíduo não é o único responsável pela construção de sua identidade, ou seja, as relações entre indivíduos, empregadores e seus representantes, diversos discursos organizacionais e discursos culturais/sociais institucionalizados são dinâmicas e recíprocas influindo diretamente no processo de identificação.

Portanto, tomando os devidos cuidados e considerando as múltiplas identificações, o amplo entendimento deste processo possibilita compreender os significados que os indivíduos "atribuem às organizações, da forma como internalizam os valores e os atributos organizacionais, de como se categorizam como membros de uma mesma organização e da relevância das organizações na sua auto definição e autoestima" (FERNANDES, MARQUES e CARRIERI, 2009, p. 688).

Entretanto, como afirma Pratt (1998), a questão de como ocorre a identificação organizacional ainda tem recebido pouca atenção. Vários pesquisadores têm proposto que os membros fazem diversos tipos de comparações de "identidade", e que estas comparações afetam suas atitudes e comportamentos para com a organização (ASHFORTH e MAEL, 1989; PRATT, 1998; DUTON, DUKERICK e HARQUAIL, 1994; ASHFORTH, HARRISON e CORLEY, 2008). Quanto maior o nível de congruência resultante deste processo de comparação maior o nível de identificação do sujeito. Segundo Foreman e Whetten (2002) este processo de comparação de identidade tem sido operacionalizado de duas maneiras:

a) A avaliação do indivíduo sobre as crenças e os valores dominantes na organização com base na sua própria auto definição (ASHFORTH e MAEL, 1989); ou

b) A comparação entre as percepções dos próprios membros do que é a identidade 
dominante da organização (real) com o que eles preferiam que fosse (ideal).

Em ambos os modelos de identificação referidos, o processo de comparação implícita ou explícita das identidades envolve um componente de avaliação e a intenção dos membros do grupo em reduzir a dissonância entre as percepções sobre "quem sou eu" e "quem somos nós" (FOREMAN e WHETTEN, 2002). Sendo assim, podemos dizer que a identificação é o nível de congruência, em determinado contexto cultural e sócio histórico, entre as percepções, expectativas e necessidades dos indivíduos com os discursos institucionais. Quanto maior o nível de congruência maior a intensidade com que os indivíduos se identificam com os discursos.

Os sujeitos também usam os atributos ou as características das organizações, enquanto objetos primordiais de identificação, como fonte de informações sobre si mesmo. Portanto, eles tendem a identificar-se com as organizações que são percebidas como de destaque em seu setor de atuação, fonte de orgulho e sentimentos positivos, pois esta posição de prestígio organizacional aumenta a autoestima dos indivíduos (TYLER e BLADER, 2003; ASHFORTH, HARRISON e CORLEY, 2008).Fazer parte de uma organização significa poder associar à sua identidade e à respeitabilidade que advém da marca da Instituição, ou seja, ser socialmente respeitado porque se trabalha em uma instituição que é fortemente respeitada na sociedade, além de sentir-se socialmente útil (SANTOS, VIEIRA e GARCIA, 2013).

Na visão de Tyler e Blader (2003), as pessoas avaliam o status de um grupo segundo sua percepção (respeito concedido) e como eles julgam que os outros irão perceber este grupo (prestígio percebido). Estes dois aspectos influenciam o processo de identificação e seus diferentes níveis de intensidade conduzem os sujeitos a se definirem como membros ou não daquela organização e a se posicionarem em relação a valores perante o próprio contexto social, num continuum que vai desde uma identificação total (superidentificação) até o desenvolvimento de estratégias de resistência fruto da desidentificação.

Em uma pesquisa realizada com policiais militares, Marra, Fonseca e Marques (2014) identificaram que os policiais vivenciavam uma situação conflituosa no que se refere ao seu processo de identificação. Os autores afirmam que os entrevistados se sentiam comprometidos com suas atividades, que se identificavam totalmente com os fins da corporação militar, mas não se sentiam totalmente identificados com todos os aspectos organizacionais, pois nem sempre concordavam com os meios empregados para atingir os fins. 


\section{Percurso teórico-metodológico: a análise crítica do discurso}

No estudo empírico, optou-se por uma abordagem qualitativa, possibilitando, desta forma, um aprofundamento nos aspectos do processo identificatório e suas configurações. Nesse sentido, a abordagem qualitativa, segundo Minayo et al. (1994), diante dos diversos significados, crenças, valores e atitudes, possibilita a apreensão dos processos e dos fenômenos, respeitando a subjetividade dos sujeitos pesquisados e abordando dimensões que não podem ser mensuradas ou quantificadas.

A pesquisa foi de caráter exploratório com a finalidade de fornecer uma familiaridade com o assunto, de descobrir e apontar caminhos (BABBIE, 1986), sem a intenção de classificar e agrupar categorias de análise. Portanto, a seleção dos entrevistados não seguiu critérios estatísticos de representatividade e proporcionalidade, permitindo, desta forma, um posterior retorno ao campo para ampliar o número de participantes e também aprofundar a análise (GODOI et al., 2006).

Para atingir os objetivos propostos nesta pesquisa, foram investigados dez indivíduos (sete homens e três mulheres) integrantes da Organização Policial, escolhidos intencionalmente em função de sua patente ou graduação, sendo assim distribuídos: um tenente-coronel, um major, dois capitães, dois tenentes, dois sargentos, um cabo e um soldado. Quanto ao tempo de serviço de cada entrevistado variou de dois anos (soldado) a 23 anos (tenente-coronel), sendo 16 anos o tempo médio do grupo. O processo de coleta de dados foi realizado por meio de observação participante e entrevistas semiestruturadas. A coleta dos dados foi realizada por um membro da própria Organização Policial que é um dos autores deste artigo, sendo possível participar do grupo e observar seu comportamento nas situações organizacionais. O corpus de análise constituiu-se dos relatos dos dez entrevistados. Para acessar o sentido das decisões dos sujeitos no que se refere aos processos identificatórios, utilizou-se da Análise Crítica do Discurso (ACD).

A ACD, vertente inglesa da análise do discurso representada por Fairclough (2003), conjuga os métodos da linguística com a ciência social crítica provendo bases para questionamentos e reflexões sobre as práticas sociais. $\mathrm{O}$ discurso, entendido como prática social, articula diferentes elementos sociais: ação e interação; relações sociais; pessoas e suas histórias, valores e crenças; mundo material; e a própria linguagem (FAIRCLOUGH, 2003). Todos esses elementos reunidos fornecem os significados do texto. Os significados compõemse em modos de agir, modos de representar e modos de ser, correspondendo a gêneros, 
discursos e estilos, respectivamente.

Para Fairclough (2003) agimos e interagimos por meio da fala e da escrita. Sendo assim, os vários tipos de gêneros são os diferentes modos de agir e interagir discursivamente. As diversas representações das práticas sociais se realizam discursivamente conforme as posições dos sujeitos nas próprias práticas. E por fim, o discurso figura na identificação, nos diferentes modos de ser que se relacionam ao estilo. Os três significados estão dialeticamente relacionados, pois cada um internaliza os outros, sendo, desta forma, analisados em conjunto. O próprio entendimento dos significados contidos nos textos produzidos por determinados sujeitos levam à revelação de suas identidades.

Portanto, por meio da verificação dos gêneros, discursos e estilos utilizados e da maneira como são articulados pelos sujeitos entrevistados em seus relatos é feita a conexão entre o processo identificatório na Organização Policial e o contexto social. Obviamente, a análise não abrange todos os recursos linguísticos dos textos nem esgota a discussão acerca das categorias analíticas utilizadas.

A linguagem, enquanto momento das práticas sociais, realiza uma interligação dialética com as ordens do discurso que encerram gêneros discursivos relativamente estáveis num determinado contexto sócio histórico cultural. Fairclough (2003) estabelece que os gêneros estão vinculados às práticas sociais que os originaram e os classificam em prégêneros, gêneros desencaixados e gêneros situados. Os pré-gêneros são categorias abstratas que compõem os situados e dividem-se em narrativas, descrições, argumentações e diálogos. Eles se aproximam dos gêneros primários de Bakhtin (1992), que correspondem às conversas espontâneas da vida cotidiana. Os gêneros desencaixados são aqueles que transcendem redes particulares de práticas e estão acessíveis a outras redes. O gênero situado trata-se de uma categoria concreta utilizada sendo característicos de uma rede de prática particular, como uma reportagem jornalística. Cabe ressaltar que, segundo o autor, um gênero situado pode englobar os pré-gêneros. Gêneros são dinâmicos, podendo ser combinados ou criados, em função das mudanças nas práticas sociais.

Uma entrevista é considerada um gênero desencaixado. Contudo, as entrevistas aqui realizadas são vistas como etnográficas por suas características e contexto de realização, sendo assim, compõem o gênero situado. As entrevistas etnográficas se assemelham com "conversações entre amigos, dentro das quais o pesquisador suavemente introduz novos elementos para ajudar os informantes a responder como informantes" (SPRADLEY, 1979, p.59).Todas as "conversações” foram realizadas no nível estratégico da Organização Policial 
durante o horário de trabalho. O locutor que conduziu as entrevistas é membro desta mesma Corporação há mais de vinte anos, possui patente superior e convive profissionalmente com todos os entrevistados. Todos os relatos foram gravados com a concordância dos entrevistados. A partir da descrição do contexto das entrevistas, pode-se inferir que o fato do entrevistador também ser policial militar proporcionou a ocorrência de pressuposições, ou seja, aquilo que é tomado pelo enunciador como consenso entre os falantes (FAIRCLOUGH, 2003). As entrevistas foram compostas de pré-gêneros, sendo predominantemente marcadas pela descrição.

Visando complementar a contextualização das entrevistas, antes de adentrar-se nas análises propriamente ditas, apresenta-se uma breve contextualização da Organização Policial em questão, a Polícia Militar de Minas Gerais.

\section{Contextualização histórica da Polícia Militar de Minas Gerais}

Classicamente, cabe ao Estado deter o denominado "monopólio da violência", ou seja, ele deve ser o responsável por manter a ordem social, coibindo conflitos, delitos e transgressões, através do uso necessário da força. Incumbido dessa função, o Estado cria mecanismos e instituições para exercê-la. De acordo com Fonseca (2013), é desta maneira que as organizações de segurança pública entram e fundamentam a sua função social, ou seja, a existência de um Estado, de forma simplificada, mas não generalizada, pressupõe a existência de mecanismos que exerçam a função de garantia do citado serviço público.

Em termos históricos é difícil visualizar qualquer sociedade em que não tenha existido uma intervenção armada para garantir a manutenção da ordem social. Portanto, é perceptível a presença da função de segurança pública de modo geral, e da polícia de maneira particular, não como existente hoje, mas em diferentes formas, tais como os exércitos que faziam vigília mesmo em tempos de paz. A sociedade egípcia, por exemplo, já possuía uma polícia com funções semelhantes às dos países ocidentais contemporâneos (MINAS GERAIS, 2007).

Nesta perspectiva, no Brasil, em 13 de maio de 1809 foi criada a Divisão Militar da Guarda Real da Polícia do Rio de Janeiro, sendo esta a primeira "força policial de tempo integral, organizada militarmente e com ampla autoridade para manter a ordem e perseguir criminosos", conforme afirma Holloway (1997, p. 47). A missão da Guarda Real deveria ser manter a tranquilidade pública, bem como as demais obrigações relativas à ordem civil (FONSECA, 2013). 
Em 1831 foi criado o Corpo de Guardas Municipais do Rio de Janeiro, por meio de Carta Régia, que também autorizava os governadores das províncias a criarem os seus respectivos Corpos. Neste prisma, em 12 de dezembro de 1831 foi criado o Corpo de Guardas Municipais Permanentes de Minas Gerais, retirando três companhias do Regimento Regular de Cavalaria. Esta é, então, a data de criação da atual Polícia Militar de Minas Gerais, força pública paga, estruturada como organização militar responsável pela manutenção da paz e da ordem na Província. A partir do século XVIII a Organização sofreu algumas importantes mudanças (MINAS GERAIS, 2007).

Dentre essas mudanças, em 1946 a então Força Pública recebeu nova denominação, passando a chamar-se Polícia Militar de Minas Gerais (PMMG). A Corporação, a partir dessa data, passou a ser considerada constitucionalmente, também, como força reserva e auxiliar do Exército Brasileiro, exercendo as atividades consideradas primordiais, quais sejam, o policiamento preventivo e o policiamento repressivo (MINAS GERAIS, 2007). Ainda, em termos estruturais, a Polícia Militar continua a ser regida por regulamentos e leis específicas que determinam responsabilidades e autoridades de seus membros de uma forma bem rígida, típica das organizações militarizadas.

Atualmente, a PMMG possui por missão: Promover segurança pública por intermédio da polícia ostensiva, com respeito aos direitos humanos e participação social em Minas; seus Valores são: Ética, lealdade, respeito, representatividade, justiça, disciplina e hierarquia. Vale esclarecer que, além da Polícia Militar de Minas Gerais, o sistema de segurança público mineiro é composto por outros três órgãos autônomos e "integrados" entre si: Secretaria de Estado de Defesa Social, Polícia Civil e Corpo de Bombeiros Militar (FONSECA, 2013).

\section{Significados do discurso dos policiais militares}

Os textos coletados nas entrevistas são repletos de fragmentos explícitos de outros textos (intertextualidade), revelados pela presença de vozes especificas representantes de diferentes ideologias e interesses particulares (FAIRCLOUGH, 2003; BAKHTIN, 1992). Por meio das vozes, é possível observar as escolhas linguísticas do locutor para representar o discurso do outro que trazem implícitos seu engajamento e posicionamento.

Dentro deste contexto, na análise dos relatos que se segue, destaca-se a presença da voz institucionalizada da Polícia em que as diferenças entre a voz dos entrevistados 1 e 5 e a voz dos agentes dominantes da corporação são praticamente anuladas, sugerindo um alto grau 
de engajamento com o que se enuncia. Neste sentido, pode-se dizer que o significado do que é ser policial militar para os sujeitos investigados revelou a interiorização dos valores institucionais, por meio da socialização secundária desses indivíduos (BERGER e LUCKMAN, 2002; DUBAR, 2005).

Em sua seleção lexical, os entrevistados ressaltaram os "valores éticos, a disciplina, normas e leis, o respeito", e a seleção dos verbos "respeitar, defender, promover, cumprir, servir, enfrentar e manter" no infinitivo impessoal demonstra a ausência de um sujeito específico. O infinitivo impessoal pode designar uma ação involuntária independente da vontade do policial militar, fato que também está marcado pela contradição explícita ("mesmo que em situações adversas e independente do ambiente") do entrevistado 1.

É ser responsável, comprometido com valores éticos que o legitimam a respeitar, defender e promover direitos inerentes ao seu semelhante, mesmo que (CONTRASTE) em situações adversas e independente do ambiente a que esteja sujeito. Cumprir normas e leis passa a ser decorrência da postura do "ser policial militar". (Entrevistado 1).

Ser policial militar é ser um referencial em disciplina e respeito. É servir à comunidade, é cumprir e fazer cumprir a lei. É enfrentar obstáculos, violência, vandalismo, para manter a ordem pública. (Entrevistado 5).

Elementos de análise do significado identificacional, as metáforas manifestam um determinado estilo nos enunciados. Para Fairclough (2001), quando utilizamos uma metáfora para significar algo, estamos selecionando a maneira como construímos nossa realidade em detrimento de outra, sugerindo filiação a um modo particular de representar os aspectos do mundo e de identificá-lo. No trecho que se segue, o entrevistado 7 utiliza a metáfora do sacerdócio em seu sentido ontológico, ou seja, para representar sua experiência enquanto policial militar. A metáfora do sacerdócio remonta ao sacrifício do sujeito em detrimento de outros aspectos da vida (dedicação, abrir mão de aspectos pessoais) que advém da própria profissão de policial e da falta do reconhecimento por membros da sociedade civil. A seleção lexical dos verbos "estudamos, trabalhamos, deixamos, somos e tentamos", todos na primeira pessoa do plural do presente indicativo, reforçam a dimensão do coletivo e de uma ação presente e habitual com sentido de continuidade. A voz do discurso religioso que surge no relato evocando a vocação sacerdotal que é eterna e perfeita como Jesus Cristo.

É como um sacerdócio. Estudamos muito, trabalhamos muito, deixamos por várias vezes a convivência familiar para terminar um trabalho. Depois disto tudo, ainda não somos reconhecidos pela sociedade como deveríamos. Mesmo assim, ainda tentamos prestar nosso serviço a qualquer custo, até com a vida, como prega nosso juramento. (Entrevistado 7). 
As avaliações também são consideradas traços marcantes do significado identificacional. Por meio das avaliações, o enunciador se compromete com o que considera desejável ou indesejável, bom ou não, pautado em processos afetivos e julgamentos valorativos (FAIRCLOUGH, 2003). A forma como os sujeitos comprometem-se nos discursos revela os modos como ele se identifica. As avaliações podem ser marcadas por atributos, verbos, advérbios ou frases exclamativas. No relato anterior com o verbo "deveríamos" no tempo condicional, o entrevistado 7 faz uma afirmação avaliativa expressando uma ação hipotética que dependeria de uma condição para se realizar, mas que não é efetivamente realizada. Dessa forma, o entrevistado se apresenta como pertencente à categoria de policial, mas explicitamente avalia que esta categoria não recebe suficiente reconhecimento social.

Nos relatos dos entrevistados 2 e 8 , ficam claras as diferentes avaliações, significados e identificações. Ambos destacam que se sentem identificados com os fins da Organização, mas não com os meios utilizados para atingir estes fins, corroborando os achados de Marra, Fonseca e Marques (2014). As avaliações estão evidenciadas pelos adjetivos que qualificam a Organização Policial como "conservadora, hierarquizada e militarizada"; pelos verbos e advérbios escolhidos para tratar sobre o comando da Corporação em que "desconsideram, vaidosos, ações desconcertantes e desastrosas"; e pelas contradições marcadas no "contudo"das orações adversativas. Diferentemente dos trechos anteriores marcados pela impessoalidade ou pelo coletivo (nós), a seleção lexical utilizada nos relatos abaixo demonstra explicitamente os posicionamentos dos entrevistados, reforçados pela utilização da primeira pessoa do singular: "procuro, meu, eu, identifico-me".

Procuro ser sempre muito responsável junto à Instituição. Porém, meu espírito crítico, meu alto grau de politização e de conhecimento de como são e se interrelacionam os grupos sociais, faz com que eu esteja constantemente analisando o complexo emaranhado de convivência dentro dos grupos de uma Instituição eminentemente conservadora, que muitos ainda taxam de "Instituição Total", a assertiva não é totalmente verdadeira. (Entrevistado 2).

Identifico-me com a missão e os princípios defendidos pela Instituição. Contudo, questiono alguns comportamentos e posturas adotados e/ou impostos sem a real necessidade. (Entrevistado 8).

Identifico-me com a forma de Organização hierarquizada e militarizada (...) com a rede de companheirismo e amizade (...). Não me identifico com algumas posturas de comando que desconsideram a capacidade e perfil dos comandados (...), com pensamentos vaidosos que desencadeiam em ações desastrosas e desconcertantes junto aos comandados. (Entrevistado 9). 
Os diferentes "nós" são destacados nos enunciados anteriores. O entrevistado 2 encara o fato da Organização Policial ser "conservadora" como negativo, enquanto o entrevistado 9 considera positivo os atributos "hierarquizada e militarizada", ou seja, o que é considerado um atributo externo indesejável para um pode ser motivo de pertencimento para outro.

Nos trechos abaixo, os entrevistados 6 e 3 fazem outras avaliações da polícia ao relatarem como se sentem identificados. Estas avaliações são marcadas lexicalmente por atributos considerados positivos pelos sujeitos: "aceitação, ascensão profissional, objetivos, valores, princípios". O entrevistado 3 ao elaborar a justificativa de sua avaliação evidencia a comparação entre os valores que ele atribui como sendo da Instituição e seus próprios valores. A menção a estes últimos revela o contexto sócio histórico da identidade, pois eles teriam sido repassados por grupos sociais diversos ao longo da trajetória pessoal.

\footnotetext{
Verifico que em diversos aspectos me identifico com aspectos da Corporação, o que inclusive permitiu a considerável aceitação e a ascensão profissional, sem, contudo, deixar de ter minhas aspirações e relações pessoais apartadas.(Entrevistado 6).
}

\footnotetext{
Sinto-me identificado com a Instituição, pois procuro assimilar e desenvolver os seus objetivos, adaptar aos seus valores e princípios, haja vista que compactuam com alguns atributos adquiridos durante minha formação pessoal e profissional. (Entrevistado 3 ).
}

Os discursos também constituem maneiras peculiares de representar os elementos sociais (FAIRCLOUGH, 2003). Discursos diferentes trazem diferentes visões de mundo, atreladas a relações sociais e identidades. Além de representar o mundo, os discursos também se vinculam a projetos de transformação deste mundo. Os modos de representar articulam-se aos posicionamentos polêmicos ou afins frente ao próprio discurso e aos outros discursos. Os diferentes "nós" encontrados nos relatos dos entrevistados, portanto, trazem em si os significados identificacional e representacional.

A prevalência, na Organização Policial, de posições fragmentadas, ambíguas, oriundas das tensões entre estruturas mentais pré-constituídas e práticas e processos oriundos da construção social dos atores organizacionais vai de encontro aos achados de Lopes et al. (2011, p. 1842) em estudo com a polícia civil do Ceará. Segundo os autores, "mesmo considerando o nível de padronização exigido em uma organização policial, até mesmo os líderes das organizações de base são divergentes em diversos aspectos da atividade e da cultura organizacional".

Diante dessa ambivalência do processo identificatório, os entrevistados 2 e 10 deixaram explícitos quais valores e princípios eles considerariam ideais, ou seja, gostariam 
que fossem atributos da polícia para que houvesse maior senso de pertencimento. A representação do que deveria ser foi marcada pela seguinte seleção lexical: "gosto, salário, respeito, entendimento, ambiente saudável, amizade, liberdade, relacionamento, pessoas educadas e dispostas a ajudar”. Todos estes atributos estão atrelados a princípios que, na visão dos entrevistados, poderiam transformar a polícia aumentando a congruência de identidades. Ao elencarem estes valores e princípios como importantes para sua identificação, os locutores deixam implícito a não existência ou a necessária melhoria em cada um deles.

Para se identificar tem que ter: Gosto pela profissão, e muito; Salário adequado; Respeito aos superiores, amizade com os pares e entendimento dos anseios dos subordinados; Ambiente saudável de trabalho; Liberdade de expressão, com o devido respeito. (Entrevistado 2).

O ambiente de trabalho e o relacionamento com as pessoas. Quando o militar convive em um bom ambiente, com pessoas educadas, dispostas a ajudar e trabalhar bem, a identificação com a instituição decorre de forma muito mais fácil e rápida.(Entrevistado 10).

Os policiais entrevistados conjugam aspectos pessoais, como amor pela profissão e gosto pelo poder, com aspectos organizacionais, como salários adequados, ambiente de trabalho e relação chefe/subordinado, como os responsáveis pela intensidade da identificação com a organização. Mostrando, desta forma, que o processo identificatório é um campo dinâmico e inacabado em que atuam muitas forças, tais como os próprios indivíduos e os dirigentes da Corporação por meio da concepção das políticas e práticas executadas no âmbito organizacional.

\section{CONSIDERAÇÕES FINAIS}

Com a finalidade de estudar o processo de identificação dos policiais com uma Organização Policial, realizou-se uma pesquisa exploratória de natureza qualitativa, em que foram investigados os discursos de dez policiais, de variadas patentes e tempos de serviço. Os significados de ação, representação e identificação foram encontrados simultaneamente nos relatos dos entrevistados. $\mathrm{O}$ aspecto acional do significado foi evidenciado na composição dos gêneros e nos aspectos da intertextualidade. $\mathrm{O}$ aspecto representacional foi abordado pela análise da interdiscursividade, ressaltando os vários discursos que se articulam com o discurso dos entrevistados. O significado identificacional foi analisado por meio das metáforas e avaliações presentes nos discursos dos entrevistados. Embora, para efeitos didáticos, os três 
significados tenham sido analisados em momentos distintos, eles estão dialeticamente relacionados.

Neste sentido, as representações (discursos) dos policiais militares identificados nas análises foram dialeticamente internalizadas em maneiras particulares de ação (gêneros) e em modos específicos de identificação (estilos). Desta maneira, foi possível verificar como discursos dos representantes do alto comando da corporação e demais discursos sociais e culturais foram atribuídos às identidades dos policiais e, ao mesmo tempo, como constituíram também sentidos de pertencimento.

Tendo-se como pressuposto que coexistem vários discursos nas organizações que podem, alternada ou simultaneamente, servir de fontes de identificação e que os sujeitos realizam movimentos comparativos entre o que são estes discursos e o que eles gostariam que fossem, o processo de identificação dos policiais militares pesquisados conduziu estes sujeitos a se definirem como membros, ou não, daquela Corporação e a se posicionarem em relação a princípios e valores, perante o próprio contexto social. Diante das contradições e ambiguidades, nota-se que tal movimento de constituição identitária é um processo sem definição fixa, fruto de uma constante negociação entre regulação externa e resistência subjetiva.

Ressalta-se que as avaliações que os policiais fazem da Corporação são diferentes, pois não existe uma polícia única, como uma entidade formal e abstrata. Coexistem vários discursos ou várias "polícias" que servem de fontes de identificação para seus membros. Mesmo se a Organização Policial fosse encarada como um único discurso, esta significaria coisas diferentes para pessoas diferentes em momentos diferentes (ASHCRAFT e ALVESSON, 2007).

Ademais, a avaliação de todos os entrevistados foi pautada na comparação de suas próprias percepções do que é a identidade dominante da polícia (real) com o que eles preferiam que fosse (ideal). Quanto maior a convergência resultante deste processo de comparação mais eles se sentem identificados. Como resultado, em um extremo, sujeitos entendem o pertencimento à Organização Policial como um "sacerdócio", que demanda sacrifício da vida pessoal em prol da identidade como policial. Nesse sentido, estes sujeitos se responsabilizam pela identificação com a Corporação, devendo apresentar determinados atributos internos, como o amor pela profissão.

Já no outro extremo, sujeitos nem sempre estão dispostos a sacrificar seu lado pessoal em prol do coletivo organizacional, pois não têm uma visão idealizada da Corporação e fazem 
suas avaliações baseadas em ganhos e perdas numa relação de troca, estabelecendo, então, uma "vinculação mais parcial, superficial e emocionalmente controlada" (FERNANDES, MARQUES e CARRIERI, 2009, p. 700). Estes sujeitos, por sua vez, responsabilizam a instituição pela relação identificatória, baseando-se em atributos organizacionais considerados desejáveis, como salários adequados.

A presente pesquisa apresenta limitações inerentes ao percurso metodológico escolhido. Como estudo de caso e pesquisa exploratória, dificulta generalizações diretas; entretanto, contribui para que se façam reflexões de nível teórico, a partirdo fenômeno estudado, bem como a partir das crenças, atitudes e valores dos sujeitos investigados e, assim, por meio de um melhor conhecimento, permite verificar qual a forma de pesquisa mais adequada para um aprofundamento futuro. Uma das questões discutidas no decorrer deste estudo, que serve como subsídio para demais investigações, é que o exame das percepções individuais em relação à identificação organizacional deve ser conjugado com a análise dos discursos organizacionais, na medida em que o indivíduo não é o único responsável pela construção de sua identidade, ou seja, as relações entre indivíduos, agentes organizacionais, discursos organizacionais e culturais/sociais são dinâmicas e recíprocas, influindo diretamente no processo de identificação. Tais relações manifestam-se no nível discursivo pela prática da intertextualidade, a qual pode ser mais bem evidenciada quando são analisados discursos diversos e suas inter-relações. Dessa forma, propõe-se para estudos futuros a inclusão de outros discursos sobre a polícia, assim como a expansão do número de relatos de seus membros. 


\section{REFERÊNCIAS}

ALVESSON, M., ASHCRAFT, K. L., THOMAS, R.Identity matters: Reflections on the construction of identity scholarship in organization studies. Organization, 15 (1), 5-28, 2008.

ASHCRAFT, K. L. ALVESSON, M. A. The Moving Targets of Dis/Identification: Wrestling with the Reality of Social Construction, paper presented at the Annual Meeting of the European Group for Organization Studies, Vienna, Austria, 2007.

ASHFORTH, B. E.; MAEL, F. A. Social identity theory and the organization.Academy of Management Review, n.14, 1989, p.20-39.

ASHFORTH, B. E., HARRISON, S. H., CORLEY, K. G.. Identification in Organizations: An Examination of Four Fundamental Questions. Journal of Management, Vol. 34 No. 3, June 2008, p.325-374.

ASHCRAFT, K. L.; MUMBY, D. K.Reworking Gender: A Feminist Communicology of Organization. Thousand Oaks, CA: Sage, 2004. BABBIE, E. The practice of social research. 4th ed. Belmont, Wadsworth Publ., 1986.

BAKHTIN, M. Marxismo e Filosofia da Linguagem. São Paulo: Hucitec, 1992.

BAYLEY, D.. Padrões de Policiamento. São Paulo: EDUSP, 2001. 267 p.

BERGER, P. L., LUCKMANN, T. A Construção Social da Realidade: tratado de sociologia do conhecimento. Petrópolis: Vozes, 2002.

BRITO, M.J. M. et al. Traços identitários da enfermeira-gerente em hospitais privados de Belo Horizonte, Brasil. Saúde soc. [on-line]. 2008, vol.17, n.2, pp. 45-57.

CARRIERI, A. P.; PAULA, A. P. P.; DAVEL, E.Identidade Nas Organizações: Múltipla? Fluida? Autônoma? In: Revista Organizações \& Sociedade. v.15 - n.45 - Abril/Junho 2008 
DUBAR, C.A Socialização. A Construção das Identidades Sociais e Profissionais. São Paulo: Martins Fontes, 2005.

DUTON, J.; DUKERICH, J. M.; HARQUAIL, C..Organizational images and member identification. Administrative Science Quarterly.1994. v.39, p.239-266.

FAIRCLOUGH, N. Discurso e mudança social. Brasília: EditoraUnB, 2001.

FAIRCLOUGH, N. Analyzing discourse: textual analysis for social research. London: Routledge, 2003.

FERNANDES, M. E. R.; MARQUES, A. L.; CARRIERI, A. de P. Identidade organizacional e os componentes do processo de identificação: uma proposta de integração. Cadernos EBAPE. BR, v. 7, nº 4, artigo 11, Rio de Janeiro, Dez. 2009.

FONSECA, J. A. Retórica e realidade na segurança pública: estudo das estruturas dos sistemas de segurança pública dos estados de Minas Gerais e São Paulo. Tese (Doutorado em Administração) - Universidade Federal de Minas Gerais, 2013.

FOREMAN, P.; WHETTEN, D.A. "Members' Identification with Mulltiple-Identity Organizations", Organization Science, 2002, Vol. 13 No 6, pp. 618-635.

GODOI, C. K.; BANDEIRA-DE-MELO, R.; SILVA, A. B. Pesquisa qualitativa em estudos organizacionais: paradigmas, estratégias e métodos. Editora Saraiva, 2006.

GOFFMAN, E.. Manicômios, conventos e prisões. São Paulo: Perspectiva. 1999.

HOLlOWAY. Thomas H. Polícia no Rio de Janeiro. Repressão e resistência numa cidade do Século XIX. Rio de Janeiro: Ed. FGV, 1997.

LOPES JR, E. P.; PAIVA, T. A.; MUZZIO, H.; COSTA, F. J. Rigidez e subjetividades: uma análise cultural em uma organização policial. Revista de Administração Pública, v. 45, n. 6, p. 1821-1845, 2011. 
MARRA, A. V.; FONSECA, J. A.; MARQUES, A. L. O processo de identificação organizacional frente à Reforma Administrativa: um estudo exploratório. Revista de Administração Mackenzie, v. 15, n. 1, p. 49-72, 2014.

MINAS GERAIS. Polícia Militar de Minas Gerais. Diagnóstico de segurança pública n. 02/2007: histórico dos organismos policiais no mundo e no Brasil. Belo Horizonte: EMPM1, 2007.

MINAYO, M.C.S., DESLANDES, S.F., NETO, O.C., GOMES, R.. Pesquisa Social: teoria, método e criatividade. Rio de Janeiro, Petrópolis, Vozes (Coleção: Temas Sociais), 16a Edição, 1994.

NOGUEIRA, G. E. G., MOREIRA, A. L. C. As formações grupais e seus efeitos nas instituições policiais militares. Revista de Psicologia - Saúde Mental e Segurança Pública, Belo Horizonte, n.1, 35-39, 1999.

PRATT, M. G. To be or not to be: Central questions in organizational identification. In: WHETTEN, D. A.; GODFREY, P. C. (Eds.), Identity in organizations: Building theory through conversations. Thousand Oaks, CA: Sage, 1998, p.171-208.

PRATT, M. G., e FOREMAN, P. O. Classifying managerial responses to multiple organizational identities. Academy of Management Review, 25 (1), 18-42, 2000.

RHODES, C., BROWN, A.D. Narrative, organizations and research. International Journal of Management Reviews, 2005, 7, 167-88.

SANTOS, A. A. D.; VIEIRA, A.; GARCIA, F. C. Identificação organizacional: o caso dos professores de uma instituição federal de ensino. Revista Gestão \& Planejamento, v. 14, n. 1, p. 3-17, 2013.

SPRADLEY, J.P. The ethnographic interview. Florida: Harcourt Brace Jovanovich, 1979. 
STETS, J.; BURKE, P. Identity Theory and Social Identity Theory', Social Psychology Quarterly63(3): 224-37, 2000.

TAJFEL, H.; TURNER, J. C. The social identity theory of intergroup behavior. In: WORCHEL, S.; AUSTIN, W. G. (Eds.), Psychology of intergroup relations. Chicago: Nelson-Hall. $2^{\text {a }}$ ed., 1985, p.7-24.

TYLER, T.R.; BLADER, S. L. The group engagement model: Procedural justice, social identity and cooperative behavior. Personality and Social Psychology Review, 2003, 7, p. $349-361$.

YBEMA, S., KEENOY, T., OSWICK, C., BEVERUNGEN, A., ELLIS, N. \& SABELIS, I. Articulating identities. Human Relations, 2009, 62(3), 299-322. 